\title{
Assessing the Planning of Public Private Partnership (PPP) in E-Government Implementation Experience in Jordan
}

\author{
Zaid Ibrahim Al-Shqairat ${ }^{1}$, Ata E. M. AL Shra'ah ${ }^{2}$, Mahmaod Ibrahim Al-rawad ${ }^{1}$ \& Mohammad Hani Al-Kilani ${ }^{1}$ \\ ${ }^{1}$ College of Business Administration and Economics, Department of Business Administration, Al-Hussein bin \\ Talal University, Jordan \\ ${ }^{2}$ Business School, Department of Business Administration, Al Balqa Applied University, Jordan \\ Correspondence: Ata E. M. AL Shra'ah, Faculty of Business, Department of Business Administration, Al Balqa \\ Applied University, Jordan. E-mail: ata1422h@yahoo.com
}

Received: October 21, 2013

Accepted: December 4, 2013 Online Published: January 20, 2014

doi:10.5539/ijbm.v9n2p124

URL: http://dx.doi.org/10.5539/ijbm.v9n2p124

\begin{abstract}
Public private partnership (PPP) is one of the main approaches that have been utilized in executing e-government program in Jordan. The main aim of this paper is to assess the adoption of PPP in the implementation of E-Government program in Jordan as one of the developing countries through assessing one stage of the three-stage model of PPP developed by (Alshqairat, 2009). This Model (3PEG) consists of three main stages; planning, implementation, and evaluation. This paper empirically tests the planning stage for PPP in the implementation of E-Government program in Jordan. The assessing planning stage addresses six dimensions of PPP: concept, justifications, requirements, the main aspects, readiness, and the strategic opportunities. Several results are reported. The findings that were supported by using quantitative and qualitative instruments suggested a significant support for all the planning stage dimensions.
\end{abstract}

Keywords: Public Private Partnership (PPP), E-Government, development

\section{Introduction}

Both scholars and practitioners agree that public and private sectors conduct their businesses in different manners at different levels. In various occasions, the efficiency of public sector exceeds its counterpart. For instance, public sector is significantly more efficient in regard to business continuity and stability than the private sector that has better reputation in their smooth adaptation in turbulent environment it operates within. Further, supporting innovation could be a another distinctive characteristic of privet sector (Osborne \& Gaebler, 1992).

Partnership can be defined as institutionalized co-operation and viable and politically attractive mechanisms between the public and private sectors which is likely to evolve as its context changes (Houghton, 2010). Consequently, Public Private Partnership (PPP) emerged as solution to enable collaboration between both sectors in several areas, including, ICT and advance technology (Hosman, 2011).

During the last two decades, government around the world in both developed and developing countries started considering PPP, mainly, as a mean of reforming public sector. For instance, in the 1990s the UK governments reform its health sector through replacing the National Health Services (NHS) to a market-driven one through collaborating with private sector (Collins et al., 2000). In similar fashion, developing countries, such as, Leabanon adopted PPPs in several fields to enhance the growth of private sector activity by participating in infrastructure, manufacturing and services such as telecommunications and energy sectors in the country (Jamali and Olayan, 2004).

PPP approach requires important factors such as governments' budget constraint, macroeconomic conditions, size of the market, potential of currency crisis, regulation, governance and political environment in determining its projects (Sharma, 2012). To prepare for appropriate PPP; the task needs to be broken into a series of defined steps and processes at the same time legal, technical, financial, environmental and other requirements will expertly be prepared correctly by public sector and managed effectively (Farquharson et al., 2011).

In parallel with the appearance of PPP, E-Government concept emerged as a governmental rationality through technological reform and by using different ICT tools and devices for developing and enhancing public sector 
agencies through addressing the common public sectors issues such as bureaucracy and duplication of public departments' efforts and manage technology dominant-hardware and software (Stahl, 2005, Henman, 2010; Singh, 2011; Anthopoulos, 2012). However, the lack of public sector experience and relative difficulties in adopting new innovation and technologies led governments seek help from privet sector though implementing different forms of PPP.

E-Government projects were usually implemented by the development of contractual relationships with the private sector, these contracts do not mean only transferring some of the public sector duties, but also transfer public power to third party to undertake the responsibility to develop and maintain the infrastructure for the public sector service provision through ICTs or providing consults to government in public service delivery (Nixon et al., 2010)

Such projects benefit both public and private sector through different advantages, ranging from working relationships to active transactions, collaboration and different types of joint ventures, subcontracting, alliances and acquisitions that included in partnership long-term arrangements (Kaliannan, 2010; Sirkemaa, 2010; Paroski, et al, 2013). Therefore, the implementation of PPP projects in E-Government created a relationship with a new link that promoted the closer integration between government stakeholders and the service providers that might be purely private sector or joint agencies that include public and private sector. In short, through this implementation, PPP facilitated a speedy development of E-Government and as a result governments have succeeded in re-shaping their roles and this emphasized the importance of partnership arrangements with other sectors such as the private and voluntary sectors (Griffin \& Halpin, 2002; Tynkkynen et al., 2012). These implementations have taken several forms which have been designed for general purposes without any consideration to the E-Government requirements.

Accordingly, the current research aims to develop a practical PPP model that meets the needs and requirements of E-Government initiatives by assessing and empirically validating a pre propose model in PPP. The used model which had been developed by Alshqairat (2009), proposed three stages through which we can successfully implement PPP in E-Government projects (planning, implementation and assessing stages). However, the focus of the current paper will be on assessing the planning aspects of the proposed model through empirically testing the model in the context of Jordan.

\section{E-Government in Jordan}

E-Government program in Jordan came in 2001 within the development initiatives and projects adopted by the country to achieve sustainable development in all aspects of people's life. It was built on four main pillars included institutional framework, legal framework, Information Communication Technology (ICT) Infrastructure and business level and implemented by Ministry of Communications and information technology (MOICT) to strengthen the provision of services electronically by using the means of communication and various technology.

This program worked as a focal point to coordinate the efforts of various ministries and institutions and to develop plans for providing government services and transactions electronically and its strategy declared that a successful implementation of E-Government in Jordan needs effective participation by different stakeholders, including private sector. (Alomari et al., 2012; MOICT, 2013; MOICT, 2013a \& 2013b).

Therefore, from the early stages of E-Government program in Jordan, a strategic collaboration with local and international enterprises has been adopted to facilitate the implantation of E-Government projects through risk sharing, promoting innovation, shared technology and decreasing costs (MOICT, 2013c). Also, the Draft Law for organizing partnership between public and private sector (2011), demonstrated the reasons for legislation for PPP that include the support of infrastructure projects, promotion of investments and offering the necessary needs for public services through mechanism works towards activation of the benefits for public sector according to government controls to public interest and decreasing the pressure on public budget.

\section{The Partnership in E-Government Model (3 PEG)}

Although, there was a vital debate about the role of PPP in E-Government implementation, the missing point was proposing a practical model for such role defining the whole picture about the steps of adopting PPP approach. Langford and Harrison (2001) argues that establishing a management framework for the partnership was one of the important challenges, particularly in the E-Government implementation. Accordingly, some researches, for instance, Al- Shqairat (2009) attempted to propose a model through which we government can successfully implement PPP in E-Government initiatives. Al-Shqairat, model of Partnership in E-Government model ( 3 PEG), as mentioned in Figure 1 below posted three main stages that should be considered by 
government while implementing PPP in E-Government initiatives. These are as following:

- Planning stage for PPP in E-Government implementation, which included defining the PPP concept, determining PPP justifications, identifying PPP requirements, identifying the main aspects of PPP, realizing the strategic dimension of PPP and PPP readiness.

- Implementation stage for PPP in E-Government implementation, which included defining the available forms of PPP, specifying the available areas of PPP, realizing the benefits of PPP, realizing the barriers of PPP and identifying the mechanisms of PPP.

- Evaluation stage for PPP in E-Government implementation, which included assessing progress aspects of PPP, and realization of the main aspects for developing it.

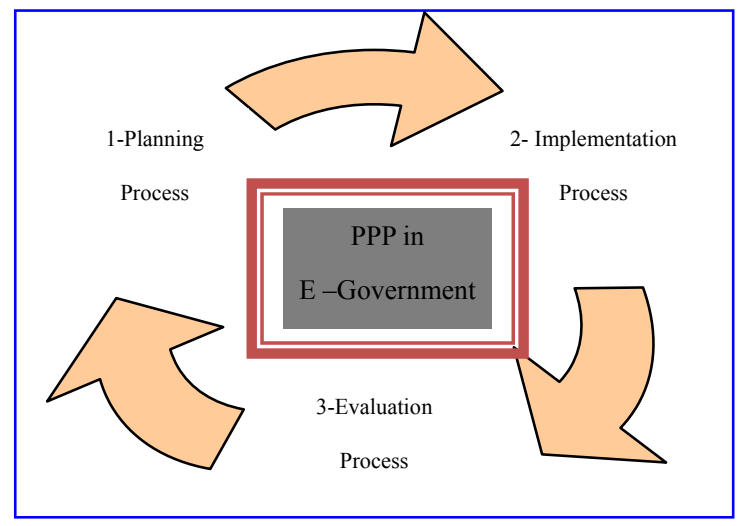

Figure 1. 3 PEG model

Source: Al-shqairat, 2009.

As stated before, the aim of the current paper is to empirically test the planning stage of the proposed model in the context of Jordan. The next section contains a detailed discussion regarding the different dimensions of the planning stage.

\section{Dimensions of the Planning Stage in the Partnership in E-Government Model}

According to the planning stage of the 3 PEG model, as mentioned in figure 2 below, the argument about the PPP concept indicated the different PPP concepts according to the different perspectives, such as the sharing of revenue, collaboration and coordinating between partners that participate in PPP projects to exchange the benefits, and neutral benefits that can be obtained from partnership. Other perspectives indicated the capacity building as a core for the PPP concept, since both private and public sectors seek to rebuild or develop their capacities in financial or human resources. As there were different concepts for PPP according to the different perspectives, the concept of PPP is still unclear and used broadly by researchers in the literature according to their perspectives about the discussed issues and the nature of the collaborative initiatives between the public and private sector, in addition to the collaboration areas.

Despite the difference between perspectives about the PPP concept, the base of any partnership is the corporation that is built on specific agreements with explicit targets that observe the differences between private and public sectors in specific areas of the collaboration. Accordingly, PPP in E-Government implementation can be defined as all the available integrated collaborative agreements between the E-Government program as a representative for all public sector institutions and the private sector, which is built on clear sharing of revenue and sharing of risks such as the high cost of the E-Government program, the conflicting decisions and lack of skills within public sector agencies, in addition to the clear exchange of benefits such as, capacity building, information, financial and human resources with consideration of the requirements of the planning, implementation and evaluation stages of each PPP project. 


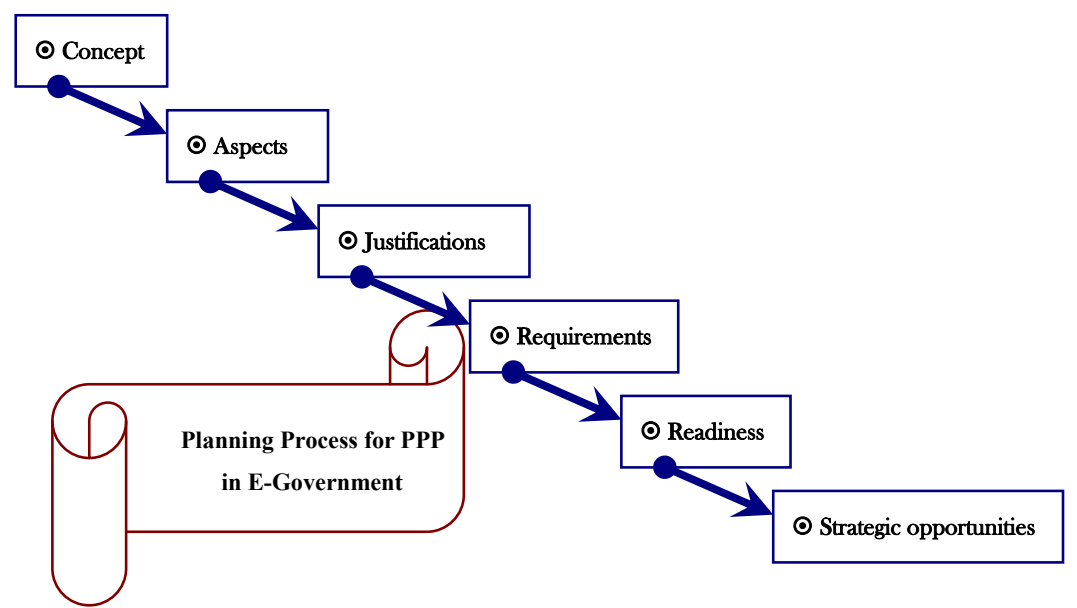

Figure 2. The six dimensions of planning process for PPP in e-government

The main justifications of the PPP approach were clarified as the main factors that justify the role of PPP in E-Government implementation, including the government proceeding towards the E-Government program itself as a permanent commitment, improving the dual relationship between partners through joint projects in E-Government, the need for integration between sectors to invest the strength aspects and to solve the weak aspects. Furthermore, PPP projects can be implemented to exchange the benefits between partners such as investing in the high security of employment in the public sector through using public sector human resources, and at the same time investing in the strong accounting and management information systems in the private sector.

PPP projects in E-Government also allow partners to exchange financial and human resources, since the private sector in Jordan has the financial ability to support the building of infrastructure for E-Government projects. Moreover, PPP can be justified by sharing the risks of E-Government projects with the private sector and continuously to transfer the risks to the private partners by the government, such risks include; the high cost of the E-Government program, the conflicting decisions among public agencies, lack of skills of public sector resources, resistance to change, and speed of change and high expectations.

The aspects of PPP have three types including training, consultation and infrastructure issues, which have been realized from the E-Government program in its early stage. Jordan has realized the need for training for the majority of public sector employees, to be able to deal with E-Government requirements, and from the planning stage there were many IT training programs for thousands of public sector employees. Most of the training contracts were outsourcing projects and not a full partnership. i.e. the establishment of a joint institution between the public and private sector to manage and undertake training process.

Moreover, the consultation aspect has two key issues; the importance of consultation for E-Government projects and the ways in which the role of private consultation companies can be developed in E-Government projects. There is an added value for consultation in the long and short terms, but the role of consultation companies in E-Government projects is still lacking and trust in such companies is not at a suitable level. Regarding the infrastructure aspect, the main components of Public Key Infrastructure (PKI) include human resources that need to address the capacity building issue, and the technology aspect that addresses the information and financial resources. Furthermore, the infrastructure for the processes and systems, that needs to address the E-payment system, E-Government operations, E-Government networks, and E-Government portal.

The requirements of the PPP role in E-Government implementation can be divided into many issues, which are seen from the country level as a whole, the public sector level, the private sector level and the public private partnership level. Nationwide, PPP requirements included leadership commitment, liberation of the services system, council and committees for PPP, a suitable environment, the PPP framework and changing the culture of the organizations.

On the Public sector level, the requirements included legislations development, coordination among government agencies, funding and infrastructure, acceptance of revenue sharing, development of public organizations' 
systems and their processes, and activating the role of consultant companies. On the Private sector level, PPP requirements included activation of consultancy companies' role in PPP, qualified ICT companies, increased collaboration with international companies, acceptance of bearing the risks, development of local ICT companies, and considering the social responsibility for citizens. PPP requirements on a partnership level included common understanding, funding and infrastructure, mutual trust, integrated knowledge and information, clear strategy for PPP, and independency for all partners.

PPP readiness involves two perspectives about PPP's maturity: The first perspective supposes that PPP is still not mature in Jordan, because there is an absence of a general framework, and the fact that the private and public sector have not changed their old culture that rejects collaboration and leads to each sector in blaming the other without good reasons, most of the time. The second perspective believes that PPP is almost mature and has continuous development in Jordan, and there are some indications of maturity such as, development of some legislation, changing of culture, PPP opportunities, and government attention towards the PPP approach.

The Strategic dimension focuses on for the opportunities of the PPP role in E-Government Implementation. Any PPP project in E-Government should concern the opportunities to prepare the suitable ways for investing them. The opportunities for the PPP approach include the continuous development in some laws, the new perspective for future and advancement from the youth leaders, international loans and grants for the E-Government program in Jordan, and good local ICT infrastructure. Also the opportunities include the impression that was given by public agencies and private sector companies in Jordan of being partners in the E-Government implementation, and the E-Government program itself supported the proceeding towards PPP by giving opportunities to all sectors to share as stakeholders in the E-Government program.

\section{Methodology}

Data of the current research were collected using two research instruments; survey questionnaire and semi structured interviews. The triangulation between these two methods enables the researchers to validate the proposed model using quantitative date, and to gain in depth information regarding PPP. Furthermore, the collected information from the interviews could act as a mean to validate the quantitative research results. Follow a detailed description of the methods and procedures used in the current research.

\section{1 Semi Structured Interviews}

The researchers decided to interview all the information technology department managers in all the 13 public organizations that have been targeted in the research project. All the organizations have been contacted by the first author either by the e-mail or the telephone to set up the meeting time with the related people, but only 9 organizations enabled him to interview their employees and 2 of the organizations enabled him to interview 2 of their employees. The interviews were semi structured in their format and conducted using a topic guide with main questions that included the following: PPP concept, PPP aspects (training, infrastructure and consultation, PPP justifications, PPP requirements, PPP readiness, Strategic dimensions (opportunities of PPP in e-government projects Jordan).

Eleven participants were interviewed by the first author, where the interviews were conducted in nine public organizations. Four of the participants were working as managers of department of Information Technology and 6 were head of divisions related to that department, only one of the participants was not in a managerial position. The participants are involved in E-Government PPP projects and they are practitioners in such projects and 4 of them were females, while seven were males. Nine of them were specialized in Information technology or computer engineering and the average of the interviews duration was 34 minutes. The interviews lasted between 21 minutes and 50 minutes with an average of 34 minutes and the participants experience were between 5 years and 23 years with an average of 12 years. Participants were asked to give their consent to record their interviews and only 3 of them agreed. The written interviews and the transcripts have been analyzed using a process of thematic coding, to identify key themes and concepts emerging from the data.

\subsection{Survey Questionnaire}

In order to empirically test the proposed planning model of PPP implementation in E-Government projects, data were collected by using a questionnaire specifically designed to test the various planning dimensions proposed by the model following details regarding the methodology used in the current paper.

\subsection{Distribution of the Questionnaire}

The collection of empirical data regarding the current research involves the distribution of a questionnaire to the target respondents. For the purposes of the current research questionnaire was designed and validated to obtain government entities feedback regarding PPP planning stage. Respondents were requested to indicate their 
practices regarding each item based on a four- point Likert scale with 1 scoring disagree to 4 scoring strongly agree (Carr, 1996). The reason for using four-point Likert scale rather than five was to avoid the neutral response-which does not make sense practically and does not give benefit due to the nature of the study (Darby, 2008).

\subsection{Population and Sampling}

The study population was comprised of public entities engaged in PPP projects. The information regarding the study population was obtained from the Jordanian Executive Privatization Commission. Thirteen different public entities have been identified to have direct involvement in PPP. Therefore, the decision was taken to target all the thirteen public entities. One hundred and ten questionnaires were administrated to the selected entities.

Table 1. Respondent according to their management position

\begin{tabular}{ccccccccc}
\hline Gender & $\begin{array}{c}\text { Assistant General } \\
\text { Secretary }\end{array}$ & $\begin{array}{c}\text { General } \\
\text { Manager }\end{array}$ & $\begin{array}{c}\text { Project } \\
\text { Manager }\end{array}$ & $\begin{array}{c}\text { Information } \\
\text { Manager }\end{array}$ & Consultant & Clerk & Others & Total \\
\hline Male & 1 & 0 & 7 & 2 & 0 & 31 & 14 & 55 \\
Female & 0 & 2 & 2 & 0 & 1 & 16 & 16 & 37 \\
Total & 1 & 2 & 9 & 2 & 1 & 47 & 30 & 92 \\
\hline
\end{tabular}

Table 2. The distribution of respondents' based on entities and the number of PPP project

\begin{tabular}{lcc}
\hline \multicolumn{1}{c}{ Source } & Frequency & \% \\
\hline Ministry of planning & 5 & 5.1 \\
National Broadband Network & 5 & 5.1 \\
E-government Program & 19 & 19.3 \\
Ministry of Water & 3 & 3 \\
Ministry of General Works and Housing & 8 & 8.1 \\
Greater Amman Municipality & 23 & 23.4 \\
Ministry of Power & 8 & 8.1 \\
Electricity Regulatory Commission & 3 & 3 \\
Ministry of industry and trade & 1 & 1 \\
Ministry of Transport & 6 & 6.1 \\
The general tenders department & 5 & 5.1 \\
Ministry of Environment & 2 & 2 \\
\hline & No. of PPP project & 23 \\
\hline Less than 3 projects & 13 & 24.7 \\
From 3 up to 6 projects & 10 & 14.0 \\
From 7 up to 10 projects & 34 & 10.8 \\
More than 10 projects & & 36.6 \\
\hline
\end{tabular}

Out of 110 questionnaires 98 were returned, of which 2 were unusable. Therefore, the gross response rate was $89.1 \%$, while the usable response rate was $83.6 \%$. The demographic profile is given in Table 1 and respondents' distribution based on entities of respondent and number of PPP project is given in Table 2. Cronbach's alpha was calculated to test the research instrument reliability. Four out of six variables were tested for internal consistency these are concept, aspect requirements, and strategic. One main variable, however, was excluded (justification) for technical reasons. Since this variable was measured in the current research using only two items. As shown in Table 3 the Cronbach's Alpha for the entire selected variable exceeded the cut-off vale and scored over 0.6 which regarded as satisfactory level in social science (Malhotra \& Birks, 2006). 
Table 3. Cronbach's alpha for all measurement scales

\begin{tabular}{lcc}
\hline Variable & Number of items & Cronbach's Alpha \\
\hline Concept & 3 & 0.801 \\
Aspect & 6 & 0.680 \\
Justification & 2 & 0.790 \\
Requirements & 4 & 0.720 \\
Readiness & 3 & 0.630 \\
Strategic & 3 & 0.637 \\
\hline
\end{tabular}

\section{Discussion}

The data obtained from the research questionnaires were analyzed in accordance with the research model. Means and standard deviations were computed for each of the research variables. Table 3 presents the overall means and standard deviation for all respondents and for the different groups of respondents based on their working place. The survey responses were coded with the values, as stated earlier, from 1 (disagree) 2 (slightly agree), 3 (moderately agree), and 4 (strongly agree).

As can be seen, the mean score of model variables indicate generally positive responses for the entire model. This represents an empirical support for the proposed PPP model. Furthermore, some variable scored higher than others including; concept, requirements, and readiness. All these variables scored more than 3 which fall between moderately agree and strongly agree.

In order to validate the current research results, across validation between entities was conducted followed by a comparison based on the number of projects. One way Anova analysis of variance showed that there were no significant differences among respondents groups.

Table 4. Comparison of variables for each group of respondents according to the respondents' place of work

\begin{tabular}{clcccc}
\hline Variable & & All respondents & Ministry & Public entity & Government Department \\
\hline \multirow{5}{*}{ Concept } & Mean & 3.33 & 3.34 & 3.49 & 3.15 \\
& SD & 0.61 & 0.66 & 0.40 & 0.56 \\
& $\boldsymbol{N}$ & 93 & 62 & 13 & 18 \\
& Mean & 2.77 & 2.75 & 2.89 & 2.77 \\
Aspect & SD & 0.46 & 0.50 & 0.45 & 0.33 \\
& $\boldsymbol{N}$ & 93 & 62 & 12 & 18 \\
& Mean & 2.83 & 2.9 & 2.79 & 2.61 \\
Justification & SD & 0.61 & 0.60 & 0.70 & 0.58 \\
& $\boldsymbol{N}$ & 93 & 60 & 13 & 18 \\
& Mean & 3.55 & 3.57 & 3.60 & 3.44 \\
Requirements & SD & 0.51 & 0.51 & 0.47 & 0.57 \\
& $\boldsymbol{N}$ & 93 & 62 & 13 & 18 \\
& Mean & 3.19 & 3.27 & 3.15 & 2.97 \\
Readiness & SD & 0.59 & 0.60 & 0.47 & 0.63 \\
& $\boldsymbol{N}$ & 93 & 62 & 13 & 18 \\
& Mean & 2.70 & 2.69 & 2.91 & 2.61 \\
Strategic & $\boldsymbol{S D}$ & 0.52 & 0.55 & 0.39 & 0.47 \\
& $\boldsymbol{N}$ & 93 & 62 & 13 & 18 \\
\hline
\end{tabular}

Furthermore, another comparison between different respondents groups was conducted based on the number of projects that had been carried out by the respondent entity. Four different groups of entities were selected based on their involvement in PPP project these groups are: less that 3 projects, from 3 to 6 projects, from 7 to 10 projects, and more than 10 projects. One way ANOVA analysis of variance showed that there was a significant difference between group (less than 3 project) mean and all the respondents mean for the aspect variable $(\mathrm{F}=4.675, \mathrm{P}=0.005)$. Table 5 demonstrated that the mean for the group was less than 3 project equal 2.5 while the overall mean was 2.77 .

The variable aspect illustrated that the variable has three different dimensions; training, infrastructure, and 
consultation. The correlation results between the six items that been used in measuring the aspect dimensions and the number of project shows that results showed that two dimensions.

Table 5. Comparison of the model variables means and standard deviations for each group of respondents according to number of project been carried out

\begin{tabular}{|c|c|c|c|c|c|c|}
\hline \multirow{2}{*}{ Variable } & & \multirow{2}{*}{ All respondents } & \multicolumn{4}{|c|}{ Number of projects being } \\
\hline & & & Less than 3 & 3 to 6 & 7 to 10 & More than 10 \\
\hline \multirow{3}{*}{ Concept } & Mean & 3.33 & 3.40 & 3.28 & 3.17 & 3.37 \\
\hline & SD & 0.61 & 0.61 & 0.60 & 0.72 & 0.48 \\
\hline & $\mathrm{N}$ & 93 & 23 & 13 & 10 & 34 \\
\hline \multirow{3}{*}{ Aspect } & Mean & 2.77 & $2.50^{*}$ & 2.73 & 2.73 & 2.96 \\
\hline & SD & 0.46 & 0.37 & 0.54 & 0.40 & 0.46 \\
\hline & $\mathrm{N}$ & 93 & 23 & 13 & 10 & 10 \\
\hline \multirow{3}{*}{ Justification } & Mean & 2.83 & 2.78 & 2.96 & 2.75 & 2.86 \\
\hline & SD & 0.61 & 0.80 & 0.52 & 0.59 & 0.54 \\
\hline & $\mathrm{N}$ & 93 & 23 & 13 & 10 & 10 \\
\hline \multirow{3}{*}{ Requirements } & Mean & 3.55 & 3.54 & 3.63 & 3.60 & 3.52 \\
\hline & SD & 0.51 & 0.37 & 0.42 & 0.49 & 0.49 \\
\hline & $\mathrm{N}$ & 93 & 23 & 13 & 10 & 10 \\
\hline \multirow{3}{*}{ Readiness } & Mean & 3.19 & 3.10 & 3.15 & 3.25 & 3.25 \\
\hline & SD & 0.59 & 0.62 & 0.59 & 0.49 & 0.46 \\
\hline & $\mathrm{N}$ & 93 & 23 & 13 & 10 & 10 \\
\hline \multirow{3}{*}{ Strategic } & Mean & 2.70 & 2.69 & 2.7 & 2.64 & 2.76 \\
\hline & SD & 0.52 & 0.57 & 0.72 & 0.46 & 0.45 \\
\hline & $\mathrm{N}$ & 93 & 23 & 13 & 10 & 10 \\
\hline
\end{tabular}

In line with the survey analysis, data collected through interview have also confirmed the importance of planning stage for the success of PPP adoption in general and in E-Government initiatives in specific. Further, the analysis of the interviews shows that IT managers have given a high importance for the planning stage, which, according to them could act as an indicator for the success or failure of any PPP project before proceeding with the implementation. The analysis also shows managers expectation and understanding of the PPP concept is similar to the proposed model and the survey results. For instance, Acting Head of Information Technology Division in the Department of Information Technology in Electricity Regulatory Commission says that the PPP concept " our understanding of PPP is that it represents a collaboration between the public and private sector, in which the private sector has more qualifications and experiences in the E-Government projects than the public sector need to fulfill them, but has less experiences, also it means the continues work with private sector to achieve the cooperation, integration, and exchange the experiences, the support and the consultation mutually".

In similar fashion, the interviews analysis has also established that PPP aspects as an important element of PPP planning stage. Although, in our model PPP aspects consist of training, infrastructure, and consultation, however, the analysis shows that the training aspect was the dominant for most of the interviewed managers, while less or no attention has been giving to infrastructure and consultation. Head of computer division in the department of Information Technology in the General Tenders Department stated that "training our employees is a success factor for our department, thus, we have done several contracts with the private sector to train our staff in Information Technology, programming, and system analysis centers in order to cope with e-government requirements. Also most of the infrastructure was built by the private companies, such as, building the networks, preparing the servers rooms and following the maintenance for the IT devices and the software".

Other elements of planning stage have also received some support from the interviews analysis, including, justifications requirements, readiness, and opportunities. Hence, interviewees indicated that PPP justifications include efficiency, ability, experience, specialization of private sector, particularly in ICT that is very important for E-Government projects, and the distribution of the roles between the public and private sector. For instance, Manager of projects and program management unit in the E-Government program in the Ministry of Communications and Information Technology states "public sector is not responsible about the executive of some ICT services, so the private sector should take the responsibility and the role in the national development, 
because it is specialist and has the ability and experience in such services". Furthermore, most of the participant agreed those PPP requirements, such as, the legal framework, legislations, regulations, and the fund should be in place to have a successful PPP planning. Others add the presence of consolidated objective and strategy and vision for PPP for all the partners.

In addition, readiness of both public and private partners should be guaranteed before starting with the PPP implementation. There was some disagreement between participants regarded readiness. Thus some participants considered readiness as an advanced level of planning stage which could come after requirements. Others, however, regard it as initial stages or even not in the planning stage at all. Although, there was some disagreement on readiness among participants, but that does ignore the fact that readiness plays an important role in PPP adoption. One explanation for this disagreement could be contributed to the participant confusing between readiness and requirements where both concepts, for some extend are similar.

The final element of the planning stage that has been tested was opportunities of PPP. The analysis showed that the majority of the participants ( 9 of them) agreed that the opportunities for PPP are the financial and material international support for PPP projects, the global orientation for PPP and the suitable local environment. For example, Manager of Information Technology and Achieve Department in the Ministry of Planning says "the opportunities are existence, but need to be taken and invested through a party that has a decision and can take this decision. The global orientation for PPP is an opportunity, the international support is an opportunity and the orientation toward the governance in private and public sector is also an opportunity".

\section{Conclusion}

This paper reported results as a part of a major research that aimed to test and validate a previously proposed model of PPP implementation in the context of E-Government program in Jordan. The 3 PEG model, suggested three main stages that should be considered for a successful implementation of PPP in E Government initiatives, these are, planning, implementation, and evaluation. Accordingly, the purpose of the current study is to develop and validate a research instrument that can be used to assess the planning stage of the PPP adoption model, further to provide an empirical support of the proposed model.

The findings that were supported by using quantitative and qualitative instruments suggested a significant support for all the planning stage dimensions. However, some elements have received higher importance than others including, concept, requirements, and readiness. This might reflect the importance of these three dimensions in the planning stage, and on the other hand might reflect the integration between the requirement for PPP and its readiness.

This also reflects the need to refining the planning stage to include two main phases ; initial part which represents a crucial elements of the planning stage including concept, requirements, and readiness and supportive phase which represents aspects, justifications and PPP opportunities)

This study can be considered as one of the few studies that attempted to propose and valid an empirical model of PPP planning in E-Government projects that could be adopted by governments while planning for a successful PPP approach in implementing E-Government initiatives in specific or an ICT related project in general. Despite the significant findings of this study, a number of limitations should be acknowledged. The research instrument was designed and validated for the purposes of the current research, however, further validation studies are required to confirm that validity and reliability of the research instrument. In addition, such research could provide other opportunities in other countries in the region. Furthermore, including private sector could provide a better understanding of PPP planning in E-government implementation.

\section{Acknowledgement}

The Authors wish to acknowledge the financial support of the "Scientific Research Support Fund" in the Hashemite Kingdom of Jordan in carrying out the research for this paper.

\section{References}

Alomari, M., Woods, P., \& Sandhu, K. (2012). Predictors for e-government adoption in Jordan Deployment of an empirical evaluation based on a citizen-centric approach. Information Technology \& People, 25(2), 207-234.

Al-Shqairat, Z. (2009). Understanding the Role of Public Private Partnership (PPP) in E-Government Implementation in Developing Countries: Case Study of Jordan. PhD thesis, Leds Metropolitan University, Leeds, UK.

Anthopoulos, L. G. (2012). An Investigative Assessment of the Role of Enterprise Architecture in Realizing 
E-Government Transformation. Project Management Department, Technological Education Institute (TEI) of Larissa.

Carr, S. C., Powell, V., Knezovic, M., Munro, D., \& MacLachlan, M. (1996). Measuring motivational gravity: Likert or scenario scaling? Journal of Managerial Psychology, 11(5), 43-47. http://dx.doi.org/10.1108/02683949610124816

Collins, C., Green, A., \& Hunter, D. (2000). NHS Reforms in the United Kingdom and Learning from Developing Country Experience. Journal of Management in Medicine, 14(2), 87-99. http://dx.doi.org/10.1108/02689230010346358

Darby, J. (2008). Course evaluations: a tendency to respond "favorably" on scales? Quality Assurance in Education, 16(1), 7-18. http://dx.doi.org/10.1108/09684880810848387

Farquharson, E., Mastle, C., Yescombe, E. R., \& Encinas, J. (2011). How to Engage with the Private Sector in Public-Private Partnerships in Emerging Markets. Washington, DC: The World Bank. http://dx.doi.org/10.1596/978-0-8213-7863-2

Griffin, D., \& Halpin, E. (2002). Local government: A digital intermediary for the information age? Information Polity, 7(4), 217-230.

Henman, P. (2010). Governing Electronically: E-Government and the Reconfiguration of Public Administration Policy and Power. UK: Palgrave Macmillan. http://dx.doi.org/10.1057/9780230248496

Hosman, L. (2011). View from practice: Making the transition from pilot to scale: examining sustainability and scalability issues in a public-private telecenter partnership in Sri Lanka. Information Technology for Development, 17(3), 232-248. http://dx.doi.org/10.1080/02681102.2011.568225

Houghton, J. (2010). Negotiating the Global and the Local: Evaluating Development through Public-Private Partnerships in Durban, South Africa, Urban Forum.

Jamali, D., \& Olayan, S. (2004). Success and Failure Mechanisms of Public Private Partnerships (PPPs) in Developing Countries: Insights from the Lebanese Context. International Journal of Public Sector Management, 17(5), 414-430. http://dx.doi.org/10.1108/09513550410546598

Malhotra, N. K., \& Birks, D. (2006). Marketing research: an applied approach (3rd ed.). Prentice Hall.

MOICT. (2013). Ministry of Information and Communication Technology. Retrieved from http://www.moict.gov.jo/en-us/egovernmentprogram/visionmission.aspx

MOICT. (2013a). Retrieved

from http://www.moict.gov.jo/en-us/egovernmentprogram/egovernmentprogramobjectives .aspx

MOICT. (2013b). Retrieved http://www.moict.gov.jo/enus/egovernmentprogram/wegovernmentprogrampillars.aspx

MOICT (2013c). Retrieved from http://www.moict.gov.jo/en-us/strategicagreements.aspx

Nixon, P. G., Koutrakou, V. N., \& Rawal, R. (2010). Understanding E-Government in Europe: Issues and challenges. New York: Routledge.

Osborne, D., \& Gaebler, T. (1992). Reinventing Government: How the Entrepreneuria Spirit is Transforming the Public Sector. New York: Addison Wesley company Inc.

Paroski, M., Konjovic, Z., \& Surla, D. (2013). Implementation of e-Government at the local level in underdeveloped countries: The case study of AP Vojvodina. The Electronic Library, 31(1), 99-118. http://dx.doi.org/10.1108/02640471311299164

Sharma, C. (2012). Determinants of PPP in infrastructure in developing economies. Transforming Government: People, Process and Policy, 6(2), 149-166.

Sirkemaa, S. (2010). Towards Integrated Electronic Services in Public Sector. Latest Trends on Computers.

Stahl, B. (2005). The Ethical Problem of Framing E-Government in terms of E-Commerce. Electronic Journal of E-Government, 3(2), 77-86.

Tynkkynen, L. K., Hakari, K., Koistinen, T., Lehto, J., \& Miettinen, S. (2012). Integrating public and private home care services: the Kotitori model in Tampere, Finland. Journal of Integrated Care, 20(5), 284-295. http://dx.doi.org/10.1108/14769011211270738 


\section{Copyrights}

Copyright for this article is retained by the author(s), with first publication rights granted to the journal.

This is an open-access article distributed under the terms and conditions of the Creative Commons Attribution license (http://creativecommons.org/licenses/by/3.0/). 